\title{
Como é ser diferente em Administração? A performance de discentes gays e bissexuais em uma graduação heteronormativa ${ }^{1}$
}

\author{
Diego Costa Mendes e José Ricardo Costa de Mendonça
}

\section{RESUMO}

Este estudo objetiva evidenciar a compulsoriedade heterossexual na graduação em Administração e sua relação com a performance de discentes gays e bissexuais do curso. Com base na compreensão sobre performatividade, performance, heteronormatividade e matriz de inteligibilidade, foram realizadas entrevistas com 16 discentes (gays e bissexuais) do curso de Administração de uma IES privada e, posteriormente, os enunciados coletados foram trabalhados a partir de análise do discurso. Percebemos que a heteronormatividade evidenciada na prática social da Administração compele práticas compulsórias aos discentes, sendo regida por normas que instigam a repetição de performances legitimadas e que se amparam na compreensão linear entre corpo, sexo e desejo. Os corpos dos discentes circunscritos no curso tendem a ser regulados com base em imposições estabelecidas a partir da compulsoriedade heteronormativa. Acreditamos ainda que a matriz heterossexual possibilita controle social na Administração a partir de elementos legitimados que projetam performances esperadas e que buscam conformar os corpos discentes sobre identidades previamente arquitetadas.

Palavras-Chave: performatividade; performance; heteronormatividade; LGBT; graduação em Administração.

\section{How is it to be different on business school? The performance of gay and bisexual students in a heteronormative undergraduate course}

\section{ABSTRACT}

This study aims to highlight the compulsory heterosexuality on business school and its relationship with the performance of gay and bisexual students. Based on the understanding of performativity, performance, heteronormativity and intelligibility matrix, interviews were conducted with 16 students (gay and bisexual) of the business school of a higher education institution and the collected statements were analyzed under the discourse analysis theory. We realize that the heteronormativity evidenced in the social practice of administration compels compulsory practices to students, being governed by rules that instigate the repetition of legitimate performances and which are supported by the linear understanding between body, sex and desire. The bodies of students circumscribed in the course tend to be regulated based on impositions established from compulsory heterosexuality. We also believe that the heterosexual matrix allows social control in business school from legitimate elements that seek to conform the student bodies to previously architected identities.

Keywords: performativity; performance; heteronormativity; LGBT; business school.

1 Agradecemos aos avaliadores pelas recomendações que contribuíram para a versão final deste texto.

Recebido em: 20/03/2020 Revisado em: 30/04/2020 Aprovado em: 30/07/2020

Check for updates

Diego Costa Mendes (iD,

Universidade Federal de Viçosa, Brasil Doutor em Administração,

Universidade Federal de Pernambuco Brasil

diegocostape@gmail.com

José Ricardo Costa de Mendonça (iD,

Universidade Federal de Viçosa, Brasi Doutor em Administração,

Universidade Federal de Pernambuco

rcm@ufpe.br 


\section{INTRODUÇÃO}

No campo da Administração, a diversidade foi inicialmente caracterizada como uma combinação de pessoas com distintas identidades se relacionando num mesmo sistema social (Nkomo \& Cox, 1999; Fleury, 2000) e algumas de suas preocupações preliminares estavam centradas em como gerir diferentes grupos nas organizações, como se trabalhar com/e a diversidade de pessoas (Hanashiro \& Torres, 2010).

Desde o surgimento de tais debates até os dias atuais é comum a utilização do termo "diversidade" nos discursos que visam trazer maior eficácia às organizações, com intuito de agregar valor a estas estruturas (Fleury, 2000; Lorentz, 2014). O entusiasmo sobre a gestão da diversidade na Administração e a máxima de que as pessoas deveriam ser igualadas por suposta comum humanidade camufla abordagem categorial que classifica e reduz as diferenças humanas a partir de agrupamentos genéricos, os quais negligenciam seu caráter dinâmico, temporal, contextual e circunstancial (Burbules, 2008).

Neste estudo, levamos em conta que a diferença é discursivamente produzida, não podendo ser apreendida fora dos processos linguísticos de significação. Ao dizer que algo ou alguém é "diferente" estabelece-se relação com outro algo pretensamente "não diferente" (hegemônico) e, por consequência, estamos inevitavelmente marcando relação de poder: o hegemônico é qualificado positivamente e normatizado como padrão legitimado, enquanto o "diferente" é apreciado negativamente e, por vezes, silenciado ou excluído (Silva, 2013).

Discussões sobre as diferenças humanas na Administração vêm dando destaque ao público LGBT (Moura \& Lott, 2016). Todavia, mesmo com a evidenciação dada no plano teórico às distintas formas de se vivenciar a sexualidade e de performar gênero, a estrutura de poder na qual a sociedade se alicerça ainda está baseada em normas que não reconhecem a multiplicidade humana. Impera no convívio social padrões baseados na noção de normalidade, que instituem como norma a heterossexualidade, enquanto excluem aqueles que nela não se enquadram.

O pensamento binário alicerçado na dicotomia existente entre a heterossexualidade e a homossexualidade favorece a hegemonia baseada na ideia de normalidade, que julga como perversão e desvio as práticas que fogem da orientação heterossexual. Os sujeitos que se posicionam fora desse modelo dominante costumam ser vistos como estranhos e desviantes. Por conseguinte, a sexualidade passa gradualmente a estabelecer "o lócus de domesticação e de controle social" que reforça as significações presentes na lógica heteronormativa, que se autojulga "divina, racional, biológica" (Swain, 2009, p. 27). Sendo assim, qualquer comportamento que não esteja em consonância com o padrão heterossexual provocaria uma descontinuidade na "tríade sexo-gênero-sexualidade", e passa a se configurar como o comportamento de uma "minoria" (Souza, 2009).

As normas regulatórias do sexo - baseadas em binários opostos: homem/mulher, macho/fêmea, masculinidade/feminilidade - têm "poder continuado e repetido de produzir aquilo que nomeiam" a partir de um caráter performativo no qual elas repetem e reiteram as normas dos gêneros 
da ótica hegemônica (Louro, 2016, p. 45). Entendemos por performatividade o sistema simbólico caracterizado por normas regulatórias que nomeiam e induzem comportamentos performativos aos sujeitos, mediante aparatos discursivos que emanam do poder hegemônico continuado (Louro, 2016). Alinhada ao ideal da compulsoriedade heterossexual, a performatividade impõe aos sujeitos normas linguisticamente constituídas e socialmente naturalizadas mediante matriz de poder que regula a performance humana por meio de "restrições sociais, tabus, proibições, ameaças de punição" (Butler, 1993, p. 21). Enquanto a performatividade reflete o sistema simbólico vigente (Somekh \& Lewin, 2015), as performances podem ser enxergadas como comportamentos performados, associadas à indução promovida pelas normas e convenções performativas (Butler, 1993), as quais restringem as possibilidades de se manifestar dentro de um contexto específico (Souza, 2017). A partir das normas subjacentes presentes nos discursos legitimados socialmente, os indivíduos passam a adotar performances que homogeneízam seus comportamentos, para que possam ser aceitos socialmente.

Frente a esse contexto, as críticas aos padrões hegemônicos necessitam ser constantemente revisitadas e aprofundadas, a fim de questionar a reprodução e perpetuação de modelos excludentes nas práticas organizacionais e no curso de Administração. Tais escolas tendem a refletir a estrutura de poder presente no corpo social, reproduzindo a heteronormatividade que vigora na sociedade e principalmente no mercado (Rumens, 2016).

É importante salientarmos aqui que a dominação masculina (Bourdieu, 1996) também se apresenta socialmente naturalizada no contexto da Administração, por meio de simbolismos masculinos, mentalidade empresarial patriarcal e valores heteronormativos que evidenciam cultura masculina sobre seu currículo, ensino e relações sociais (Kelan, 2013; Petinelli-Souza, 2013). Especificamente ao que se refere à graduação em Administração, pesquisas realizadas em Escolas de Administração em diversos países refletiram a generificação dos discentes e o não estímulo por parte das teorias administrativas à reflexão sobre como as diferenças são hierarquizadas com base no padrão hegemônico (Higashi, 2016). Tal contexto nos leva ao questionamento central deste estudo: como a heteronormatividade na Administração pode estar relacionada à performance de estudantes gays e bissexuais do curso?

O presente estudo tem por objetivo evidenciar a compulsoriedade heterossexual na graduação em Administração e sua relação com a performance de discentes gays e bissexuais do curso.

Visamos com esta pesquisa preencher alguns gaps na literatura em Administração sobre gênero e sexualidade. Moura, Nascimento e Barros (2017, p. 1482) evidenciam que "a homofobia nas organizações e a adesão a políticas de diversidade são apenas a ponta do iceberg do escopo possível que envolve as questões referentes à população homossexual nas organizações". Os preconceitos tanto no mundo social quanto no organizacional promovem uma visão naturalizada da Administração que, por sua vez, invisibiliza sujeitos que não correspondem ao padrão hegemônico da heterossexualidade e diminui o espaço concedido para discussões a eles relacionadas. 
Além disso, a naturalização da heterossexualidade e da masculinidade na Administração constitui influente discurso que reforça socialmente ideais estéticos ligados à aparência e ao comportamento, aos quais homens e mulheres deverão se adequar (Teixeira, Perdigão, \& Carrieri, 2016), rejeitando aqueles(as) que ameaçam a heteronormatividade ao pôr em xeque o padrão heterossexual legitimado (Moura, Nascimento, \& Barros, 2017). Diante deste contexto, faz-se necessário discussões como as apresentadas no presente estudo, que lançam luzes sobre a realidade daqueles(as) colocados às margens das preocupações e problematizações deste campo.

A relevância deste trabalho se evidencia por meio de suas contribuições acadêmicas, já que a pesquisa expande o debate sobre sexualidade e heteronormatividade nos estudos organizacionais e, mais especificamente, sobre o curso de Administração; e pela centralidade dada às experiências de discentes gays e bissexuais no ambiente educacional, problematizando as relações de poder baseadas na sexualidade nesse ambiente.

Além desta introdução, este artigo segue discutindo acerca da performatividade e da performance, e da hegemonia heterossexual na Administração; descreve os procedimentos metodológicos adotados na construção da pesquisa; apresenta e analisa os enunciados coletados por entrevistas; e finaliza com discussões sobre a análise dos dados, seguida das considerações finais que o estudo possibilitou.

\section{A REGULAÇÃO PELA PERFORMATIVIDADE E A REPETIÇÃO DAS PERFORMANCES}

Aquilo que fazemos e dizemos não é fruto de uma essência interior subjetivamente real e natural. $\mathrm{O}$ que continuadamente dizemos e fazemos nos constitui como real e natural (Borba, 2014). Essa reflexão pode ser explicada a partir do modelo performativo da identidade discutido por Butler (2017). Segundo a autora, o que muitas vezes enxergamos como essência e composição natural de nossas identidades são performances constantemente repetidas que reforçam discursos.

Entendemos por performance a maneira como os indivíduos se apresentam e tentam controlar a percepção que outras pessoas têm dele, podendo ser baseada naquilo que se pode ou não fazer (Goffman, 1959). Entretanto, não é possível afirmarmos que a intenção do sujeito que fala determina, por si só, a totalidade de seus atos (Derrida, 1990). A performance humana não é sempre consciente ou intencional. Ela é produto da repetição compulsória das normas históricas, culturais e sociais que regulam a sociedade por meio do discurso e está associada ao poder vinculado a ele (Butler, 1993a; Borba, 2014).

O discurso, por sua vez, é articulado a partir de uma matriz de inteligibilidade composta por normas socialmente legitimadas, que servem de pano de fundo para a fabricação do sujeito mediante práticas sociais continuamente reproduzidas (Souza, 2017). A matriz de inteligibilidade (Butler, 2017), também chamada de matriz heterossexual ou heteronormativa, é uma maneira simbólica de organizar e conceder significado aos corpos, atribuindo 
sentido de coerência entre a identidade de gênero e a sexualidade. A citada matriz estabelece que o ser humano deva corresponder a apenas um gênero, e que essa conformidade se dá em razão do seu sexo, produzindo aparente encadeamento entre sexo, gênero, desejo e prática sexual, além de auferir inteligibilidade àqueles corpos que apresentam estabilidade e unidade entre essas categorias (Butler, 2017).

Os corpos podem ser vistos como elementos regulados por normas ritualizadas, as quais nele estão inscritas e que ao mesmo tempo postulam prévias significações. Pinto (2007, p. 12) esclarece-nos que "o corpo tem seus limites irredutíveis, porque nele estão inscritas as regulações sociais, não como representações das estruturas de poder, mas como parte dessas estruturas". As normas que regulam a performance linguística e social não são simplesmente reflexos de uma estrutura existente, mas também elementos de criação e recriação da própria estrutura. O sujeito seria um ser performativo que repete ações para circunscrever sua identidade no tempo (Cameron, 1995).

A performatividade "funciona como uma rede de premiações e punições que confere e afirma um poder vinculado sobre a ação performada, que acontece e é operada por meio do discurso" (Souza, 2017, p. 316). Pode ser concebida como uma pré-condição de existência do sujeito (Jagose, 1996), que viabiliza, reforça e também restringe a performance mediante códigos de significação (Sullivan, 2003; Cameron \& Kulick, 2003), desafiando a compreensão do senso comum de que o comportamento humano não é uma simples exteriorização do Eu interior (Cameron \& Kulick, 2003); tanto estimula a repetição de atos e ritos, mesmo com a ausência de seu referente, quanto de significados e intenções não tão claramente determinados (Pinto, 2007).

A performatividade está ainda relacionada com a estilização reiterada do corpo, o qual é submetido a princípios normativos de coerência advindos da lógica da compulsoriedade heterossexual (Butler, 2003a; Jagger, 2008).

\begin{abstract}
As instâncias que condicionam o corpo como alvo das condutas normativas delimitam os ambientes pelos quais os indivíduos estilizados devem habitar nos espaços sociais. O esforço da incidência, por uma perspectiva heteronormativa compulsória, de uma identidade cultural repleta de atos e ações que devam ser coerentes, demonstra o excesso de adestramento ao qual o corpo é submetido (Bravo, 2015, p. 116).
\end{abstract}

A estilização causa efeitos sobre a anatomia e sobre a sexualidade, por estar ancorada sob a lógica binária e reprodutora homem-mulher, reforçando a heterossexualidade compulsória e "postulando a única possibilidade do sujeito" (Pinto, 2007, p. 22).

As performances de gênero não ocorrem voluntariamente e sim dentro de um cenário discursivo repleto de imposições e coerções que limitam aquilo que é reconhecido em dado contexto - a exemplo da Administração -, funcionando como uma rígida estrutura que demarcará as possibilidades de performar (Butler, 2017). Assim como outras categorias identitárias, o gênero também é performativo, produto de normas regulatórias que distinguem e hierarquizam as diferenças por meio de "restrições sociais, tabus, proibições, ameaças de punição", que passam a instituir caráter homogêneo e estável 
daquilo que vem a constituir, por exemplo, a masculinidade e a feminilidade (Butler, 1993, p. 21). Tal concepção sobre gênero consolida e naturaliza essa produção, normatizando os corpos, e excluindo quaisquer sujeitos que destoem da matriz de inteligibilidade (Pinto, 2007; Butler, 2017).

A pluralidade, a instabilidade, a indecisão ou mesmo a mudança são encarados previamente com estranheza e passam a ser submetidos a inúmeras formas de violência. Conforme Pinto (2007, p. 25) "o controle intencional das identidades inteligíveis escapa ao sujeito, ao mesmo tempo que implica suas possibilidades ritualizadas de existência".

Para Butler (1993a, 2017), tanto o sexo quanto o corpo são efeitos discursivos que se materializam a partir de sua significação cultural, encontrada a partir de códigos de significação e estruturas reguladoras que Ihes atribuem, ou não, inteligibilidade mediante conformidade com estruturas discursivas heteronormativas. Para a autora, quando se enuncia expressões como "é uma menina" ou "é um menino" no nascimento de uma criança, por exemplo, se descreve um estado de elementos anteriores à enunciação e, ao mesmo tempo, faz-se com que o corpo ao qual tais enunciados se dirigem seja pressionado pelas normas regulatórias (Butler, 2017).

Ao serem transportados para distintos contextos e indivíduos, os signos linguísticos que compõem a matriz de inteligibilidade produzem, concomitantemente, continuidades, descontinuidades, fissuras e rupturas, abrindo espaço para subversões que podem propiciar mudanças nesse processo e desarmonias, por exemplo, na conformidade esperada entre corpo, sexo, gênero, desejo e performance (Borba, 2014). As mencionadas rupturas podem "apontar formas de subjetivação que resistem de maneira a constituir sujeitos singulares, seres que produzem diferenças" (Miskolci \& Pelúcio, 2007, p. 258).

Amparados em Butler (1993), ressaltamos a importância da performatividade não ser entendida como a verdade interior do sujeito, muito menos como a performance que este desempenha no meio social. Isso porque performatividade e performance não suportam a mesma carga de sentido. Enquanto a performatividade reflete o sistema simbólico carregado de normas que antecede, submete e sobre-excede a vontade do indivíduo que executa a ação, regulando a repetição dessas normas. Ademais, as performances podem ser entendidas como comportamentos performados, frutos da indução promovida pelas normas e convenções performativas (Butler, 1993).

A performatividade compele práticas compulsórias ao comportamento humano, todavia não pode ser compreendida como determinante na formação do sujeito. É constituída por normas que instigam a repetição, no entanto, a intenção a ser atingida se encontra em uma posição ideal, que não é alcançada do mesmo modo que é performada (Sullivan, 2003). Isso nos leva a perceber que o ato de repetir permite uma série de possibilidades de mudança e subversão à lógica performativa e à matriz de poder que a sustenta (Souza, 2017).

O ideal heteronormativo presente nas relações sociais conduz a comportamentos performados associados a normas reguladoras $e$ normalizadoras que emanam da matriz de poder, e que também permanecem cristalizadas no curso de Administração. Dessa forma, acreditamos ser pertinente discutir a seguir acerca da hegemonia heterossexual na Administração. 
A HEGEMONIA HETEROSSEXUAL NA ADMINISTRAÇÃO

Há uma hegemonia masculina histórica sobre a esfera do trabalho e da Administração, tendo influência sobre "o que é produzido, estudado e difundido sobre as organizações" (Cappelle, Melo, \& Souza, 2013, p. 163). Sob o alicerce da razão e da objetividade - características associadas regularmente à masculinidade -, as organizações foram constituídas desde as Revoluções Francesa e Industrial sobre elementos masculinizantes, e seguiram seu desenvolvimento pela modernidade respaldadas no tradicionalismo da cultura patriarcal, contexto no qual os valores e atributos tidos como femininos são subjugados aos masculinos (Cappelle, Melo, \& Souza, 2013).

Apesar de ser frequente a defesa de discurso que as organizações são ambientes neutros e que pregam a igualdade, sua estrutura, cultura e simbolismo geralmente dissimulam e reforçam assimetrias de poder e desigualdades tanto de gênero (Benschop \& Doorewaard, 1998) quanto de sexualidade. Comumente, as diferenças de gênero e de sexualidade estão implícitas nas estruturas e nos processos organizacionais, (re) produzindo continuadamente tais distinções por meio de diversos arranjos organizacionais (Cappelle, Melo, \& Souza, 2013). Cristalizados por teorias organizacionais, padrões tendem a ser internalizados, transformando-se em verdades inquestionáveis neste contexto.

Em pesquisa realizada com profissionais da Administração, Shimada e Crubellate (2012) evidenciam que a constituição do perfil profissional do sujeitoadministrador ainda está fortemente associada às regras, normas e parâmetros presentes nas práticas discursivas e em dispositivos ligados ao curso, como manuais de conduta, disciplinas da grade curricular na graduação, projeto pedagógico do curso e revistas de negócio, direcionando e influenciando "o que deve fazer e o que deve ser" o sujeito-administrador.

Na maioria das vezes, o sujeito-administrador é compelido a se comportar e a utilizar-se das práticas legitimadas, restando pouco espaço para que possa refletir sobre sua identidade e sobre o papel que exerce. Por meio de sujeição, tais indivíduos buscam ocupar o espaço designado a sua profissão, conforme o que se espera de tal figura, restando pouca crítica, autonomia e reflexão sobre sua autoconstituição. É comum encontrar profissionais desta área resignados sob os discursos predominantes (Shimada \& Crubellate, 2012), estado prolongado desde sua formação e sob influência dos manuais, modelos e técnicas que alicerçam a graduação em Administração.

Nesse contexto, "há uma mentalidade empresarial que governa a todos" e que se encontra não só como um pré-requisito da profissão de administrador, como também na graduação em Administração - pautado num "deslumbramento por um tipo de desenvolvimento e modo de vida que passaram a servir como referência", mas que são repletos de inconsistências (Petinelli-Souza, 2013, p. 479).

Higashi (2016) chama atenção que parte considerável dos estudantes desse curso reproduz o discurso do "politicamente correto", reproduzindo 
valores morais heteronormativos presentes na sociedade. A partir deste indicativo, o autor evidencia caráter heteronormativo sobre a Administração, apresentando que tal particularidade pode estar relacionada a padrão reforçado pelo ensino e pelas pesquisas na área, indo contra a suposta neutralidade no campo da produção do saber e do ensino.

A heteronormatividade se constitui como fator organizador da vida social, na qual não se percebe sua presença, mas se sente seus efeitos (Berlant \& Warner, 1998; Butler, 2017; Higashi, 2016). No entanto, as teorias administrativas não parecem legitimar que tanto as estruturas quanto os processos organizacionais são intercortados por relações de poder baseadas no gênero (Morgan, 2007; Reed, 2007) e também na sexualidade. Dessa forma, Reed (2007) evidencia a importância de se estudar a questão de gênero - a qual somamos a temática sobre sexualidade - como instrumento de análise nos estudos organizacionais, e como estas modelam a vida e o espaço organizacional.

Alguns dos signos que ilustram a heteronormatividade sobre a Administração podem ser vistos na linguagem e nas metáforas majoritariamente masculinas, além dos estereótipos reproduzidos sobre o feminino e o masculino na gestão (Hearn, 1992). Soma-se ao contexto apresentado, o retrocesso quanto à criação de políticas públicas para a educação voltadas às minorias e à diminuição do preconceito e discriminação contra os LGBT. Além de valores heteronormativos, entram em jogo no cenário político brasileiro valores de cunho religioso que, deturpadamente utilizados, atribuem a noção de anormalidade às diferenças de orientação sexual e de identidade de gênero.

Ao investigar estudantes da Administração, Higashi (2016) percebeu que a heteronormatividade presente no curso está relacionada ao modo como estes julgam o que é verdade, a saber, linguagem inteligível e comportamento normal, a partir de valores trazidos do contexto externo às IES. Segundo o autor, tal percepção ainda pode ser estimulada pela própria estruturação do currículo do curso, marcada pelo silenciamento diante de temas em torno das diferenças.

Tais pesquisas existentes têm demonstrado que há predominância de cultura masculina sobre o currículo, o ensino e as relações na Administração, o que contribui para a não importância dada a temáticas relativas à diversidade de gênero (Kelan, 2013) e de sexualidade tanto no futuro exercício profissional dos discentes quanto acerca das relações tecidas sobre a prática social do curso.

Além da identificação de ethos masculino sobre a graduação, há indicativo de certa instrumentalidade do conteúdo vivenciado na Administração para atender à ideologia hegemônica. Apesar das diferenças humanas e diversidade sexual fazerem parte da vida em sociedade (e do contexto organizacional, a exemplo do educacional) e estarem presentes nas discussões do cotidiano, pouco é argumentado sobre elas no ensino da Administração e pouco também são questionadas pelas teorias e nas práticas dessa área do conhecimento (Swan, Stead, \& Elliott, 2009), fatos que corroboram a naturalização do padrão heteronormativo sobre a dinâmica social do curso. 


\section{PERCURSO METODOLÓGICO}

Esse estudo possui abordagem qualitativa, na busca por evidenciar a compulsoriedade heterossexual na graduação em Administração e sua relação com a performance de discentes gays e bissexuais do curso.

O ponto de partida para a realização da pesquisa de campo se deu com a definição do lócus onde a investigação se daria: uma Instituição de Ensino Superior (IES) privada, localizada na cidade do Recife. A definição da instituição se deu por acessibilidade, já que conseguimos autorização formal prévia para a realização da pesquisa na instituição. Entretanto, outros parâmetros foram avaliados concomitantemente, como: a oferta de curso de graduação em Administração e a presença de discurso da IES pautado no respeito às diferenças e à inclusão - mesmo que não formalizado.

O corpus da pesquisa foi composto a partir de enunciados coletados em entrevistas semiestruturadas, com 16 discentes (9 gays e 7 bissexuais) de distintos períodos do curso de Administração, conforme descrito no Quadro 01. As entrevistas tiveram duração média de 45 minutos cada e foram realizadas entre setembro e outubro de 2018.

Todos os entrevistados assinaram Termo de Consentimento Livre e Esclarecido. Ao término de cada conversa foi solicitado que cada discente escolhesse um nome fictício, diferente do seu, a fim de ser identificado(a) e ao mesmo tempo manter o anonimato das declarações.

Neste trabalho, os enunciados coletados pelas entrevistas foram tratados sistematicamente, possibilitando identificar os distintos discursos presentes no texto e interpretá-los a partir de análise do discurso. Foi possível acessar as discursividades presentes nos textos coletados e perceber o modo como os sentidos estavam sendo produzidos e as condições dessa produção, a fim de "compreender melhor o que [estava] sendo dito" (Orlandi, 2002, p. 42). "Como a linguagem é, em última instância, produto da ideologia" (Saraiva, Santos \& Pereira, 2019, p. 119), e esta se constitui "mecanismo estruturante do processo de significação" (Orlandi, 2002, p. 96), buscamos identificar os posicionamentos ideológicos adotados pelos sujeitos e a produção de sentidos a partir da posição destes no curso de Administração. 
Quadro 01: Quem são os(as) entrevistados(as)

\begin{tabular}{cccccc}
\hline $\begin{array}{c}\text { Nome } \\
\text { Fictício }\end{array}$ & Gênero Declarado & Orientação Sexual & $\begin{array}{c}\text { Orientação Sexual } \\
\text { Pública }\end{array}$ & Idade & Período \\
\hline Ana & Feminino & Bissexual & Não assumida & 28 & $6^{\circ}$ \\
Bruna & Feminino & Bissexual & Assumida & 20 & $2^{\circ}$ \\
Caio & Masculino & Homossexual & Assumido & 26 & $1^{\circ}$ \\
Carlos & Masculino & Homossexual & Assumido & 25 & $6^{\circ}$ \\
César & Masculino & Homossexual & Assumido & 23 & $8^{\circ}$ \\
Eduardo & Masculino & Homossexual & Reservado & 31 & $6^{\circ}$ \\
Evaristo & Masculino & Bissexual & Reservado & 25 & $8^{\circ}$ \\
Felipe & Masculino & Homossexual & Reservado & 25 & $7^{\circ}$ \\
Isadora & Feminino & Bissexual & Reservada & 19 & $4^{\circ}$ \\
José & Masculino & Homossexual & Assumido & 25 & $3^{\circ}$ \\
Júnior & Masculino & Bissexual & Assumido & 22 & $8^{\circ}$ \\
Lorenzo & Masculino & Homossexual & Assumido & 29 & $1^{\circ}$ \\
Marcelo & Masculino & Bissexual & Não assumido & 18 & $1^{\circ}$ \\
Maria & Feminino & Bissexual & Assumida & 23 & $1^{\circ}$ \\
Miguel & Masculino & Homossexual & Assumido & 23 & $2^{\circ}$ \\
Rafael & Masculino & Homossexual & Reservado & 24 & $7^{\circ}$ \\
\hline
\end{tabular}

Fonte: Elaborado pelos autores.

A análise de discurso sobre os enunciados coletados foi conduzida a partir: i) de análise lexical: baseada nos vocábulos utilizados pelos entrevistados nos enunciados discursivos para se comunicar; ii) de elementos e percursos semânticos: na tentativa de compreender a carga de sentido dada pelos sujeitos ao se expressarem; iii) de elementos interdiscursivos: que denotem a articulação de tipos distintos de discurso e processos particulares de interpretação (Fairclough, 2016); iv) de distintos discursos identificados nos enunciados; v) de elementos ideológicos sustentados ou contestados nestes discursos; vi) e na posição dos enunciados quanto ao discurso heteronormativo, ora hegemônico na sociedade.

Nesta pesquisa, os enunciados coletados permitiram interpretar a produção de sentidos a partir de 3 categorias discursivas: 1) idealização sobre o curso de Administração; 2) currículo do curso e ensino; e 3) profissional da Administração e contexto de trabalho, que serão apresentadas e discutidas a seguir.

\section{ANÁLISE}

\section{Idealização sobre o curso de Administração}

Ao serem questionados sobre a percepção que têm sobre a graduação cursada, foi possível identificar nos enunciados elementos que sublinham a heteronormatividade no curso de Administração. 
até brinquei quando entrei na faculdade, que eu escolhi um curso muito hétero para fazer parte [...] e eu continuo com essa percepção, porque é pouquíssimo, é por conta do quantitativo de gays na sala. [...] Na verdade eu não sei explicar por que o curso é assim. Caio

O curso de Administração reflete as nossas diferenças no nosso cotidiano, não sei se dá para entender. Reflete a sociedade. [...] Você tira da questão, por exemplo, do quanto a boa parte da turma são conservadores. Do quanto boa parte da turma é daquela linha da 'família tradicional brasileira'. [...] Quando digo que reflete a sociedade é porque são como toda sala, [...] essas diferenças existem, mas estão lá cada uma no seu quadrado. Maria

Eu acho o curso de Administração muito preconceituoso. [...] No curso de Administração, pelo menos, eu acho que essas pessoas heterossexuais elas conseguem se expressar melhor. Assim, não são todas, porque têm aquelas pessoas que são na delas também, sem ser (LGBT), mas eu acho que elas conseguem se expressar mais, né?! Conseguem ter uma amizade mais fácil com outras pessoas, entendeu? Principalmente, um amigo gay meu. Ele não consegue se enturmar com todos, porque algumas pessoas vão olhar meio assim, entendeu? Então acho que o fato de ser hétero ajuda mais no convívio [...] na faculdade. Isadora

As seleções lexicais "muito hétero", "conservadores", "família tradicional brasileira" e "muito preconceituoso" são utilizadas nos enunciados em referência ao curso de Administração, evidenciando percursos semânticos que fazem referência ao discurso heteronormativo presente neste contexto social, o que corrobora com as impressões de Higashi (2016) sobre a hegemonia heterossexual na graduação.

Além de Caio ressaltar olhar quantitativo acerca do pequeno número de não heterossexuais em sua turma, tanto Maria quanto Isadora identificam por meio de elementos mais qualitativos a já citada heteronormatividade sobre o contexto. Maria recorre em seu texto a interdiscurso sobre "família tradicional brasileira", traçando aparente paralelo entre o conservadorismo de parte da sociedade brasileira e de parte dos discentes da turma, evidenciando a reprodução de preconceitos no cotidiano do curso. Ressalta ainda que a categorização social utilizada na sociedade para diferenciar e hierarquizar sujeitos (Butler, 1993, 1993a) também é adotada na divisão social da sala de aula - "Quando digo que reflete a sociedade é porque são como toda sala, [...] essas diferenças existem, mas estão lá cada uma no seu quadrado" -, reproduzindo as assimetrias de poder que refletem da forma como nossa sociedade está organizada e como o poder é nela distribuído (Orlandi, 2002).

Ao mencionar "pelo menos, eu acho que essas pessoas heterossexuais elas conseguem se expressar melhor", Isadora faz menção implícita à presença de preconceitos que dificultam a socialização dos que têm orientação sexual não hegemônica. Os corpos que possuem linearidade entre o sexo, o gênero e a sexualidade são mais facilmente inteligíveis (Butler, 2017), o que facilita a inclusão e o convívio dos heterossexuais na citada prática social, ao passo que se dificulta a socialização daqueles sobre os quais se enxerga incoerência. Os olhares também mencionados por Isadora - "algumas pessoas vão olhar meio assim" - denotam as expectativas e exclusões alinhadas a uma ideologia heteronormativa compartilhada e reproduzida no âmbito do curso. 
A partir da constatação da existência da diferença e da não conformação de alguns corpos discentes aos imperativos da performatividade, os enunciados refletem que a heterossexualidade se constitui como normal e natural na prática social do curso, tendo como consequência a exclusão do outro desviante, o que torna o convívio social mais fácil para aqueles que se enquadram na matriz de inteligibilidade heteronormativa e mais difícil para aqueles que nela não se inserem. Com isso, é possível depreender dos enunciados que, assim como demandado em espaços mais amplos da sociedade, há neste contexto social expectativas quanto à compatibilidade de gênero e de sexualidade em relação à materialidade dos corpos discentes (Colling, 2018).

A mencionada heteronormatividade produz alguns estereótipos sobre o curso:

Já me perguntaram muito: 'ah, mas tu assim... por que tu tas fazendo Administração? Porque não é curso de viado!' As pessoas têm também essa seleção aí! São essas coisas que eu venho dizendo: 'não, minha gente! Tem sim, tem viado que é dentista, tem viado que dá aula, tem no sei o quê... Viado não é só estilista e cabeleireiro não! Eles fazem outras coisas também'. [...] As pessoas acham que a gente não é capaz de fazer as coisas, porque a gente é viado! Tem isso. Lorenzo

Para ser administrador você tem que ter um perfil muito sério, e é quando você liga LGBTs a cursos assim, porque normalmente as pessoas ligam LGBT a arte, história, mas nunca a Administração, Direito... Porque é como se não fosse um curso para você, não é um curso que vá the contemplar [...]. Mas geralmente é assim: 'não é que seja um curso tão adequado para você, você não se encaixaria tanto nesse curso. Você não tem personalidade para assumir uma postura de liderança [...]. Talvez você não tenha maturidade suficiente'. [...] Usam isso como desculpa para lhe desqualificar, dependendo da sua sexualidade e gênero. Júnior

É possível identificar nos enunciados de Lorenzo e Júnior que as expressões lexicais "não é curso de viado", "Viado não é só estilista e cabeleireiro", "as pessoas ligam LGBT a arte, história, mas nunca a Administração", "não é um curso que vá lhe contemplar" apontam para discurso que estereotipa e limita o exercício profissional dos LGBT, excluindo de seu possível escopo de atuação a Administração.

A fala de Lorenzo reflete imaginário social sobre a referida graduação ser um curso heterossexual e, sendo assim, não haveria nela espaço para aqueles que possuem orientação sexual e, principalmente, performance "desviantes" do que rege a matriz heteronormativa. Os dois entrevistados expressam estereótipos que cerceiam os LGBT a um nicho específico de profissões "adequadas", geralmente aquelas ocupações ou áreas categorizadas como femininas ("estilista", "cabeleireiro", "arte"). Apesar de não estarem explícitos no discurso, os fragmentos enunciados revelam a subalternidade atribuída à feminilidade, enquanto se valorizam características, profissões e lugares associados ao masculino (Cappelle, Melo, \& Souza, 2013).

Ao mesmo tempo, o discurso acessado reflete a inferiorização dos LGBT por meio de seleções lexicais depreciativas - "não é capaz", "tão adequado", "maturidade suficiente" e "desqualificar" - com o intuito de inabilitá-los. São fragmentos reproduzidos a fim de sustentar ideologia que legitima uns e rejeita outros - reforçando por meio da "linha coerente entre sexo-gênero-desejo e 
prática sexual" a heterossexualidade compulsória e a heteronormatividade (Colling, 2018, p. 30).

A limitação ou incapacidade atribuída ao LGBT para exercer certas profissões (descritas por Lorenzo) e os estereótipos que os desqualificam por serem diferentes (citados por Júnior) representam formas de segregação que reprimem essa população quando se trata de formação superior e profissionalização, refletindo as consequências negativas da heteronormatividade presente no curso de Administração - como também em outras ocupações e áreas, conforme foi aludido pelos léxicos "dentista" e "direito" -, as quais alimentam inseguranças naqueles que são diferentes e que têm interesse em cursar tal graduação.

Os relatos de alguns entrevistados mostram que a percepção da heteronormatividade sobre a Administração também reforça estereótipos acerca do perfil de aluno predominante no curso (branco, homem, heterossexual, de ideologia conservadora), os quais, ao mesmo tempo, estimulam a falsa ideia de que não pode ser cursado por pessoas que se distanciem em demasiado desse padrão estereotipado.

\begin{abstract}
No começo, de fato, eu fiquei um pouco mais receosa por... assim, você tem uma ideia que o curso de Administração é normalmente hétero e tal. Você já vai com aquela ideia de pessoas de direita, conservadoras e tal. Aí eu fui assim com o pé atrás claro [...]. O curso de Administração para mim é formado de pessoas brancas, héteras, que tinham um posicionamento... para mim na sala só ia ter eu de esquerda, que tem um pensamento ligado com a esquerda. Pensava também que não teria tantos gays como encontrei na sala. E... [...] A sala não é extremamente branca, existem negros dentro da sala, e eu fiquei muito feliz por isso. Maria

Como eu te falei, eu pensei muito antes de fazer, porque a gente tem aquela imagem de que o curso de Administração é um curso bem normativo. Tanto é que [eu] ficava assim... 'Meu Deus do Céu, eu vou chegar nessa sala de aula e vai tá todo mundo... aquele povo sério de Administração e vai chegar eu assim na sala' [aponta para si]. Então, foi bem difícil eu querer vir para cá e tal, mas aqui, quando eu cheguei na sala de aula, eu sou muito de observar... sentei, eu primeiro observei as pessoas em volta, para ver se ia rolar ou não. Porque se eu visse que não tinha condição eu não ia vir. Porque eu passei muito tempo da minha vida obrigado a conviver numa sala de aula com pessoas que não me queriam ali, então, agora eu tenho, graças a Deus, esse poder de escolha. Mas aí, eu disse: 'Não! Eu vou, vou ser o que eu sou sempre... e aí as pessoas vão se manifestar, então aí a gente vai ver o que rola ou não'. Lorenzo
\end{abstract}

Quando se estabelece o paralelo entre o que é considerada a ideologia de direita - "pessoas de direita, conservadoras", "pessoas brancas, héteras" - e a ideologia de esquerda - "pensamento ligado com a esquerda", "gays", "negros" -, há, no texto de Maria, o interdiscurso que opõe diferentes pautas políticas no cenário nacional e que contrapõem o caráter conservador do discurso da extrema direita - caracterizado por rechaço e indiferença às minorias e à valorização da hierarquização atribuída às diferenças humanas à posição mais inclusiva do discurso da esquerda - mais sensível às pautas LGBT, por exemplo. É interessante perceber que o paralelo estabelecido pela discente aproxima a percepção que tem sobre a prática social do curso de Administração à ideologia de extrema direita, logo, ao discurso conservador apregoado a essa visão de mundo e às críticas a ele direcionadas no atual contexto histórico do Brasil. 
No texto de Lorenzo fica claro que o discente se enxerga como alguém que perceptivelmente não performa de acordo com os limites estabelecidos culturalmente pela matriz de inteligibilidade - "aquele povo sério de Administração e vai chegar eu assim na sala' [aponta para si]". Tal impressão associada às experiências vividas em outros espaços - "eu passei muito tempo da minha vida obrigado a conviver numa sala de aula com pessoas que não me queriam ali" - justificam os mecanismos de autodefesa que utiliza para conviver com os atos de preconceito a que está vulnerável, e que revelam as exclusões (e assimetrias) que a não linearidade à performatividade impõem ao sujeito diferente.

É possível identificar nos textos tanto de Maria quanto de Lorenzo a referência ao discurso heteronormativo sobre a graduação em Administração, o que gera uma impressão negativa sobre a possibilidade de inclusão e convívio com a diferença - em especial a não conformação entre sexo, gênero e sexualidade (Borba, 2014). O ideal normativo salientado sobre o curso (Higashi, 2016; Shimada \& Crubellate, 2012) - "Administração é um curso bem normativo" - por si só indica perfil e performances legitimadas nesse contexto, as quais constituem a primeira barreira à inserção do sujeito diferente.

\section{Currículo do curso e ensino}

Com relação ao dia a dia na graduação, a maior parte dos entrevistados alegou que pouco se discute sobre diferenças ou ainda que não acreditam que tal formação prepara para lidar com as diferenças no mundo do trabalho, como pode ser observado nas falas a seguir:

Eu acho que ainda está muito vago, porque, a única vez que eu vi falando sobre sexualidade, sobre diversidade, foi no $4^{\circ}$ período, na disciplina de Gestão de Recursos Humanos, que uma professora passou um seminário, não foi nem um tema da aula dela, ela passou um seminário, um grupo foi e falou sobre diversidade, ela discutiu alguns pontos e só, não tive mais contato. Rafael

Esse assunto da questão de gênero, de orientação sexual quer dizer, é... só duas vezes eu acho que tocou no assunto. Uma que foi a professora de Administração, que ela foi adentrar a questão das empresas que usam [...] a causa para ganhar em cima. E a outra foi a de comunicação que veio falar sobre a questão do preconceito dentro da empresa. Mas, assim, são formas bem rápidas de falar o assunto. Não é muito tocado, não é muito debatido. [...] Existe essa ausência do assunto. Não só da questão da orientação sexual, mas uma forma geral mesmo das diferenças. Maria

É possível reconhecer nos textos a utilização de seleções lexicais explicitando percursos semânticos que revelam a escassez de discussões sobre gênero e sexualidade no curso de Administração: "muito vago", "não foi nem um tema da aula dela", "discutiu alguns pontos e só", "formas bem rápidas", "Não é muito tocado, não é muito debatido" e "ausência do assunto", revelando que tais temáticas são ora silenciadas, ora secundarizadas pelos docentes. Mais especificamente no enunciado de Maria, pontua-se que a utilização de temáticas envolvendo, por exemplo, a questão de gênero e de orientação sexual em sala de aula é feita a partir de exemplos passageiros que não são discutidos pelos docentes com a complexidade que possuem, o que leva a discente a questionar a falta de iniciativas para abordar tais conteúdos. 
Ainda sobre os argumentos que reforçam a percepção de grande parte dos entrevistados sobre o curso não preparar seus discentes para lidar com as diferenças, Júnior recorre intertextualmente à estrutura curricular da graduação:

\begin{abstract}
Pra gente não fica claro não. Tanto que a gente só discutiu isso em uma disciplina sobre questão de gênero, de diferenças na empresa, na organização, a gente só discutiu isso em uma disciplina. No resto, que me lembro, é a gente que fala... os próprios alunos. Mas no plano curricular [do curso] eu não me lembro não de ter nada falando sobre as diferenças não, só em uma mesmo, foi no $5^{\circ}$ período, o resto eu não lembro de ter nenhuma. Júnior
\end{abstract}

Os elementos discursivos levantados por Júnior levam-no a contestar a ausência de espaço para se discutir gênero e sexualidade na sala de aula, como isso dificulta que os discentes enxerguem tais temáticas com clareza e consigam se utilizar dos saberes e da linguagem a elas relacionadas em seu contexto profissional. A inquietação de Júnior se alinha a observações feitas por Higashi (2016) de que a percepção dos discentes sobre tais temáticas pode deixar de ser estimulada pela forma como o curso estiver estruturado, e que o silenciamento pode ressaltar a não neutralidade existente nesse campo de ensino.

Ao consultar as diretrizes curriculares nacionais da graduação em Administração (Brasil, 2005), podemos perceber a inexistência de preocupações relacionadas diretamente com a compreensão e o lidar com as diferenças humanas. Há um claro direcionamento ideológico das diretrizes às questões que envolvem o processo produtivo e seu gerenciamento, as negociações, as formulações matemáticas, o desenvolvimento de projetos e consultorias etc., apontando para a instrumentalidade do conteúdo vivenciado na Administração (Swan, Stead, \& Elliott, 2009). As preocupações alusivas aos sujeitos humanos são reduzidas às entrelinhas de expressões amplas e generalistas como "expressar-se de modo crítico e criativo diante dos diferentes contextos organizacionais e sociais", "consciência da qualidade e das implicações éticas do seu exercício profissional", "transferir conhecimentos da vida e da experiência cotidianas para o ambiente de trabalho" (Brasil, 2005, s.p.).

Os relatos dos entrevistados parecem reforçar a ideia de que é "bastante comum a prática de repetir o currículo mínimo preconizado pelo Conselho Federal de Educação" (Martins et al., 1997, p. 239), dando ênfase aos critérios técnico-gerenciais exigidos e negligenciando as disposições de estímulo subjetivo e reflexivo, principalmente sobre a importância e centralidade humana no contexto sócio-organizacional - excluindo o discurso sobre diferenças de orientação sexual e de diversidade de gênero enunciadas por Júnior.

O silêncio percebido pelos discentes pode revelar o alinhamento ideológico da matriz curricular e do ensino ao discurso da heterossexualidade compulsória, perpetuando a reprodução de práticas heteronormativas que contribuem para a naturalização e manutenção do estado das coisas, da matriz de poder heterossexual e, consequentemente, das assimetrias neste espaço social (Butler, 2017; Pinto, 2007). Ao excluir ou silenciar questões sobre gênero e orientação sexual no currículo do curso, as Escolas de Administração mantêm inquestionável o padrão normativo que subjuga 
outras sexualidades distintas à heterossexualidade (Ozturk \& Rumens, 2014). Ainda como consequência, podemos ponderar que a não reflexão sobre as assimetrias de poder no contexto organizacional e nas relações de trabalho contribuem, mesmo que indiretamente, para a manutenção da estrutura de poder e para as formas de exclusão.

A maneira como o discurso sobre o ensino na Administração está estruturado reforça imaginário normativo sobre o perfil e a performance do que é ser administrador(a), reverberando traços normalizadores sobre as práticas sociais estabelecidas no cotidiano do curso e influenciando a forma como discentes percebem o curso e o profissional da Administração, como discutiremos na categoria discursiva a seguir.

\section{Profissional da Administração e o contexto de trabalho}

Quando questionados sobre como enxergam o perfil de um profissional formado em Administração, a maioria dos entrevistados apontam inicialmente características de comportamento, em sua maioria subjetivas, como organização, pontualidade, comprometimento e, principalmente, a seriedade. Os termos "sério" ou "seriedade" e "formal" ou "formalidade" foram recorrentemente utilizados ao serem relacionados à figura do(a) administrador(a). Por diversas vezes, os léxicos são enunciados como adjetivação distante do estereótipo construído sobre os LGBT.

Se fosse uma pessoa em questão [não heterossexual] que tinha que ser uma pessoa mais séria para estar naquela área. [...] A questão de seriedade seria... para quem é gay, vamos dizer, e é uma pessoa muito solta, uma pessoa muito afeminada ou alguma coisa do tipo, não que seria uma coisa para você ficar, como geralmente eu falo, 'para voltar pra dentro do armário', mas pelo fato de um padrão do gestor ser uma pessoa mais séria uma pessoa mais focada, que demonstra ser uma pessoa mais focada né, pra estar naquela [posição], pra as pessoas querendo ou não the respeitarem pelo fato de você estar demonstrando seriedade. [...] Aí às vezes a gente tem aquele perfil de mais sério para que eles tentem nos respeitar, a gente sabe que querendo ou não, nesse caso, nós estaríamos nos adaptando a eles e não eles se adaptando para serem liderados por nós naquela área. José

Eu pensaria isso como uma pessoa bem formal. Formal mesmo. Tanto no comportamento quanto na questão até do traje mesmo. Isso na questão de sexualidade qualquer pessoa pode se enquadrar, mas se existe é uma formalidade no seu profissional. A sua vida fora do profissional não importa. Acho que sempre tem que ter uma formalidade no perfil do administrador. [...] Qualquer tipo de sexualidade pode se enquadrar no perfil [...]. Mas só que tem que ter uma formalidade no ambiente de trabalho, entendeu? [...] A formalidade que eu apresento na faculdade. A pessoa formal, que não gosta de escandalizar. Era esse o termo que eu queria usar. Eu acho que todo profissional tem que carregar isso. Seja qualquer área, não só administrador, fosse um advogado, fosse um professor. Evaristo

Os léxicos "séria", "seriedade", "focada", "formal", "formalidade" e "padrão do gestor" foram semanticamente relacionados ao comportamento esperado pelo(a) profissional da Administração; ao mesmo tempo, são utilizados como contraponto aos léxicos "quem é gay", "solta", "afeminada", e explicitados por meio do fragmento discursivo "A questão de seriedade seria... para quem é gay”. É possível perceber que os enunciados reproduzem 
valores morais e estereótipos sobre os LGBT a partir de discurso do que seria "politicamente correto" (Higashi, 2016), numa clara reprodução de padrões heteronormativos internalizados.

A seriedade e a formalidade ressaltadas parecem reproduzir discurso que transforma em rotina textos convencionados e naturalizados (Fairclough, 2016). Dessa forma, performances fora da matriz de inteligibilidade heterossexual são reprimidas e, como citado por Evaristo - "A formalidade que eu apresento na faculdade" - , o comportamento adotado é adaptado aos imperativos da performatividade. É possível perceber como o discurso heteronormativo opera vigilância sobre as performances dos discentes no espaço educacional (Louro, 2016), incitando o autoexame e o autocontrole na busca por aceitação e reconhecimento neste ambiente (Saraiva, Santos, \& Pereira, 2019).

Tais recursos podem ser vistos como meios de projetar e negociar a autoimagem (Goffman, 1959), a partir do que se é instituído como performances aceitas ou rejeitadas de acordo com o padrão hegemônico heterossexual. É relevante ressaltar o caráter nem sempre consciente ou intencional da performance humana, que pode ser compreendida como produto da repetição compulsória das normas históricas, culturais e sociais que regulam a sociedade por meio do referido discurso heteronormativo (Butler, 1993a; Borba, 2014). Logo, ser gay e/ou performar fora dos eixos normativos da performatividade é combatido, pois o discurso hegemônico proclama que "qualquer coisa que desvele a homossexualidade é repulsiva e tem de desaparecer" (Saraiva, Santos, \& Pereira, 2019, p. 124).

No fragmento "A sua vida fora do profissional não importa", enunciado por Evaristo, é possível identificar interdiscursivamente a negação do Eu (Fairclough, 2016). Ao expressar tal excerto, o discente pressupõe a negação de sua própria vida e de sua sexualidade, na busca por reconhecimento e sentido de coerência no mercado de trabalho.

Em ambos os enunciados, a conjunção adversativa "mas" é utilizada como estratégia de polidez (Fairclough, 2016) a fim de reparar atos de fala que possam indicar exclusão ou sugerir a ocultação da sexualidade e/ou performance de gênero. O recurso discursivo utilizado pelos enunciadores suaviza discriminações aos sujeitos não alinhados à compulsoriedade heterossexual, ao mesmo tempo em que reafirma a opressão do discurso heteronormativo sobre estes corpos.

Paralelamente, José também explicita os imperativos de adaptação dos LGBT a parâmetros heteronormativos, mesmo quando estes ocupam cargo de maior poder na organização - "pra estar naquela [posição], pra as pessoas querendo ou não the respeitarem pelo fato de você estar demonstrando seriedade. [...] nós estaríamos nos adaptando". A reflexão do discente remete ao discurso que pode indicar a sobreposição da performatividade e da compulsoriedade heterossexual sobre a estrutura organizacional e, por conseguinte, sobre as relações de trabalho nela existentes. Tal indução ilustra a existência de dispositivos simbólicos e normativos ligados a constituição do sujeito-administrador (Shimada \& Crubellate, 2012), e pode demonstrar como a heteronormatividade pode emergir de maneira sutil na prática social organizacional, instituindo e naturalizando performances, além de estabelecer a heterossexualidade como o padrão a ser seguido (Higashi, 2016). 
Alguns entrevistados corroboram com a discussão que aqui tecemos por destacar elementos simbólicos associados à maneira de se vestir do(a) profissional da Administração:

\begin{abstract}
Uma pessoa mais séria, né? Uma pessoa que saiba falar, que saiba se expressar. E que ande bem arrumada. Usar roupa bem formal. Sei lá, se vestir bem. Isadora

Eu vejo uma pessoa [...] vestida formalmente, óbvio. Gerindo alguma empresa ou gerindo alguma equipe. [...] Um homem sempre alinhado, com cabelo feito, curtinho, com barba feita, com paletó, com unha curta. E mulher com a unha devidamente cortada, não muito grande, mas também não muito pequena, cabelo grande e maquiada. [...] Para a sociedade, o normal seria isso... algo que a sociedade veja como que não seja errado. César
\end{abstract}

O discurso sobre a imagem do(a) profissional da Administração apresenta percursos semânticos atrelados a perfil hegemônico ("séria", "formal", "alinhado") usados comparativamente ao ideal estético e comportamental heteronormativo. Ao salientar o que seria viável na questão imagética do(a) profissional da Administração - "Um homem sempre alinhado, com cabelo feito, curtinho, com barba feita, com paletó, com unha curta. E mulher com a unha devidamente cortada, não muito grande, mas também não muito pequena, cabelo grande e maquiada" -, há também a presença de interdiscurso implícito do que não seria aceitável para este ator social com base no padrão normalizado.

O fragmento discursivo "Para a sociedade, o normal seria isso... algo que a sociedade veja como que não seja errado" remete à construção social associada ao ideal de normalidade, baseada em sistema simbólico que regula performances (Butler, 1993). César enuncia a própria performatividade e, implicitamente, a rede de convenções e coerções performativas a ela atrelada, a qual organiza e concede sentido de coerência à identidade de gênero e de sexualidade a partir de traços que reforçam a masculinidade do homem e a feminilidade da mulher (Butler, 2017). A disseminação do modelo associado à matriz heterossexual possibilita controle social por meio de elementos legitimados e universalizantes, que naturalizam o imaginário estereotipado e instituem padrão tradicional ao buscar resignar os corpos sobre identidades previamente concebidas (Pinto, 2007).

Ainda sobre o tópico vestimenta, Lorenzo tece comentários sobre imposições acerca do visual do administrador e como as relaciona a sua performance:

Assim, antes de eu querer fazer [Administração] aqui, eu tenho alguns amigos gays e que são da área. E aí eles sempre disseram 'você tem que fazer porque é emprego certo e não sei o que lá'. Mas aí eu faço 'minha gente o que eles esperam? Será que eu vou conseguir dar?'. Essa questão do visual, por exemplo, que meus amigos sempre falam isso, que 'Ah! Tu vai trabalhar na área de Administração, tu vai ter que se vestir de tal forma, [...] tu não vai poder frequentar certos lugares e tal'. E eu faço 'minha gente isso não influencia!', mas eu já tenho essa consciência que se eu arranjar um emprego na área administrativa a proposta vai ter que ser outra, entendeu? Eu vou ter que fazer uma reconstrução de imagem para poder atender o que eles querem. [...] Eles querem uma visão normativa tanto dos homens como das mulheres. Lorenzo 
Percebemos que a forma como os discentes acreditam que serão enxergados enquanto profissionais tende a influenciar a maneira como performam no curso ou como pretendem performar no trabalho - "eu já tenho essa consciência que se eu arranjar um emprego na área administrativa a proposta vai ter que ser outra". Lorenzo pressupõe a necessidade de uma "reconstrução de imagem" diferente daquela com a qual se apresenta cotidianamente, na tentativa de gerenciar as impressões que por ventura se destinem a ele no contexto de trabalho da Administração. A seleção lexical reflete a resignação ao discurso normativo, apesar do entrevistado conseguir constatar que as expectativas destinadas ao perfil profissional estão alicerçadas numa "visão normativa" sobre a figura do homem e da mulher dentro da matriz heteronormativa - a qual estabelece os requisitos que farão com que estes possam ser reconhecidos e legitimados socialmente.

As paráfrases de amigos gays de Lorenzo - "tu vai ter que se vestir de tal forma, [...] tu não vai poder frequentar certos lugares e tal" - sinalizam como a performatividade permite a repetição de atos e ritos mesmo com a ausência de seu referente, ou de significados e intenções não tão claramente determinados (Pinto, 2007). Os ideais performativos instigam a programação de performance antes mesmo de se ocupar cargo de administrador, prédefinindo e regulando comportamentos linguísticos e sociais com base no discurso hegemônico (Butler, 1993a, 1998; Pinto, 2007) - conforme foi aludido por Lorenzo através da seleção lexical "que eles querem".

O entrevistado também destaca como a vestimenta pode se constituir elemento que masculiniza ou feminiza o sujeito social, podendo ser utilizada como recurso de "camuflagem" - léxico utilizado pelo discente - e/ou de adaptação às normatizações impostas no ambiente de trabalho, as quais diferenciam e corporificam o que é ser homem e o que é ser mulher, bem como as demandas de performance do que se espera deles (Butler, 2017). Podemos identificar ainda no enunciado o ideal imagético associado ao padrão heteronormativo, a partir do qual os corpos são ou não legitimados e as performances são reconhecidas ou rechaçadas (Saraiva, Santos, \& Pereira, 2019).

Alguns entrevistados sugerem que indivíduos afeminados, por exemplo, não passam credibilidade ou não impõem respeito, algo que para eles apresenta-se como importante na relação de trabalho.

Têm uns que... como posso dizer, não mancha a imagem né. Mas
têm uns que não sabem se comportar. Como a nossa classe já é
preconceituosa, tem gente que ajuda a ter esse preconceito mais ainda,
pela forma de agir, forma de falar, forma de... tipo assim, até se vestir.
[...] Como posso dizer, vamos minimizar. Porque lógico que todos têm
que respeitar, até porque respeitar é fundamental né?! Nós vamos fazer
por onde, [...] tipo ficar na sua, agir como uma pessoa normal, não ficar
com escândalos na rua, esses tipo de viadagem. [...] A maioria do povo
normal, hétero, não faz esse tipo de baixaria que alguns [homossexuais]
fazem, aí era bom que todo mundo agisse normal, já que quer ser aceito
na sociedade, é bom agir normal. Eduardo

Por vezes, a performatividade é acessada por discentes LGBT como parâmetro para a construção de julgamentos sobre aqueles que destoam do modelo hegemônico. Muitos desses discentes se reprimem e moldam suas performances a partir daquilo que é legitimado pelos padrões de 
normalidade e passam a igualmente a julgar os que se distanciam da matriz de inteligibilidade. Diversos percursos semânticos no enunciado de Eduardo denotam a ideia de inferiorização - "mancha a imagem", "não sabem se comportar", "escândalos", "viadagem", "baixaria" -, numa clara aderência ao discurso de normalidade que reforça significações heteronormativas (Swain, 2001) e julga como transgressão os comportamentos destoantes da matriz heterossexual (Butler, 2017), em especial a afeminação (Moura, Nascimento, \& Barros, 2017).

Ao observar o enunciado acima é interessante pontuar que discentes afeminados e expressivos, por exemplo, são responsabilizados por "ajudar" para que práticas de intolerância e desrespeito ocorram, culpabilizando os oprimidos por tal opressão. Na culpabilização da vítima de preconceito (LGBT afeminado) por não se adequar ao padrão conservador de comportamento (Saraiva, 2016), há a defesa de discurso normalizador e heteronormativo - "fazer por onde, [...] tipo ficar na sua, agir como uma pessoa normal" -, na tentativa de justificar o silenciamento que muitos LGBT são submetidos como meio de se adequar ou estar mais próximos do padrão de normalidade e masculinidade legitimado pela sociedade e pela maioria no curso. A associação entre ser heterossexual e ser normal, intertextualmente realizada por Eduardo, evidencia a influência da performatividade vigente sobre o discurso de alguns LGBT do curso, excluindo do imaginário projetado sobre o que é ser uma "pessoa normal" daqueles que não se ajustam aos ideais heteronormativos.

Nas diversas generalizações realizadas pelo entrevistado, ser gay e afeminado quase que se associa diretamente ao "fazer baixaria". Na busca pela autopreservação por acreditar estar mais próximo de um pretenso ideal de normalidade, o enunciador ao mesmo tempo nega o outro desviante a partir de hierarquização de suas performances e também se coloca no contexto de uma pretensa anormalidade ao associar a heterossexualidade à normalidade, haja vista que se reconhece enquanto homossexual - o que constitui uma autonegação.

A hegemonia heterossexual presente no ambiente profissional parece também exercer influência sobre os julgamentos de estudantes LGBT acerca das performances destoantes da matriz de inteligibilidade:

Exemplo, o comportamento de [Junior] na faculdade, eu acho que ele não deveria levar ele para o mercado de trabalho, para o trabalho em si. Apesar que sabemos que existe flexibilidade na cultura de cada organização, mas acho que... por exemplo, o gestor tem que ter um bom comportamento. Evaristo

O enunciado poderia nos levar à questão: o que seria "um bom comportamento"? A seleção lexical utilizada por Evaristo com fins valorativos sobre a performance de Júnior está amparada nos discursos da masculinidade e da heteronormatividade, os quais servem de alicerce para se rejeitar aqueles que não se adequam a estas construções sociais. Aos olhos do discente - e de parte dos demais entrevistados - traços de feminilidade não são vistos como performances aceitáveis para um profissional homem na Administração. Esse e outros relatos - como os que recriminaram a feminilidade e os comportamentos expressivos por parte de estudantes gays - sugerem pretensa recusa ao feminino (Cappelle, Melo, \& Souza, 2013), 
e podem revelar interdiscursivamente implícita misoginia ao rebaixar o que é enxergado como comportamento de mulher e, ao mesmo tempo, inferiorizar os gays que se comportam com traços de feminilidade (Saraiva, Santos, \& Pereira, 2019).

Mesmo ciente da recriminação direcionada ao seu comportamento, Júnior não vê como dissociar a forma como se reconhece de sua performance no trabalho, apesar de crer que tais traços fora dos moldes heteronormativos possam trazer consequências para sua vivência profissional:

\begin{abstract}
Tipo eu vou me formar, eu vou ser um profissional, então não adianta, essas questões religiosas, de gênero, raça, não deveriam influenciar em nada na minha relação com os funcionários. Não tem que influenciar. Por que influenciar? Não tem necessidade de influenciar, mas vão influenciar e é ruim. Porque não tem como mudar meu jeito, eu sou afeminado aqui, na rua, em qualquer lugar, não tem como mudar isso. Júnior
\end{abstract}

O fragmento discursivo nos revela como a performatividade que circunscreve o contexto do curso e o campo de trabalho da Administração exerce influência sobre a performance dos sujeitos nela presentes. Júnior já prevê as pressões as quais será submetido por ter comportamento distinto daquele idealizado para a profissão na qual está se qualificando e se questiona sobre quais rumos tomar já que não enxerga possibilidade de mudar seu jeito - conter seus traços afeminados. Com isso, podemos enxergar na performance de Júnior certa subversão à ordem hegemônica (Butler, 2017), ao contrariar e desarmonizar a linha coerente entre sexo, gênero e performance (Colling, 2018; Borba, 2014).

Como Butler (1993) já salientou, a busca por reconhecimento social é condicionada pelo discurso que nomeia, categoriza e hierarquiza as identidades sociais. No caso de Júnior, essa busca provavelmente não se concretizará por completo. Diante do exposto pelo entrevistado, frente à impossibilidade de se enquadrar totalmente às normas discursivas heteronormativas requeridas socialmente, podemos prever uma contínua sensação de incompletude e instabilidade na vida profissional de Júnior e de outros discentes, alimentada pelo aparelhamento ideológico que reforça tais normas compulsórias (Butler, 2017). A partir do discurso discente, é possível perceber como a ideologia dominante sobre a Administração reforça discurso hegemônico da masculinidade e da heteronormatividade.

\title{
DISCUSSÃO
}

Os enunciados coletados corroboram com as alegações de que a graduação em Administração é um curso heteronormativo (Higashi, 2016). Foram inúmeros os elementos relatados pelos entrevistados que reforçaram o pressuposto da heteronormatividade sobre a graduação, como: o conservadorismo presente no curso; o estereótipo de profissional presente no imaginário discente (homem, formal, sério, vestido de terno); a exclusão ou silenciamento de temáticas sobre gênero e orientação sexual no currículo e nas salas de aula do curso; as imposições para adequação da performance discente aos princípios da matriz de inteligibilidade. 
A heteronormatividade percebida na prática social da Administração parece distanciar sujeitos que não se enquadram no modelo heteronormativo, por gerar insegurança acerca da vivência nesse ambiente. Além disso, também é possível perceber na Administração aparelhamento discursivo sexista e misógino, que exalta comportamentos masculinos à proporção que inferioriza femininos (Cappelle, Melo, \& Souza, 2013). Essa desigualdade estabelecida entre masculinidade e feminilidade pode ser observada sobre as atitudes hostis a respeito das performances dos estudantes afeminados, evidenciando que o ideal sobre a figura do(a) profissional da Administração não é apenas heterossexual, mas sobretudo masculino. Por se distanciarem do modelo de masculinidade arquitetado pela matriz de poder, tais discentes são julgados e preteridos, inclusive por outros alunos gays que possuem performance mais próxima da heteronormativa.

Diante do exposto pelos entrevistados, conseguimos perceber na graduação de Administração a estrutura de dominação masculina e heterossexual sobre os demais gêneros e orientações sexuais. A estrutura de poder sob a prática social do curso desencadeia relações de desigualdade e discriminação - no significado explícito da palavra -, distinguindo, diferenciando e segregando com base nos princípios instituídos pela matriz de inteligibilidade.

Há ainda aqueles que se silenciam frente à constatação de que não se adequam ao modelo de identidade legitimado pela ordem simbólica vigente, restringindo suas performances. A ordem do discurso na Administração parece demandar de seus estudantes a estilização constante de seus corpos, tornando as performances cada vez mais homogêneas.

Alguns entrevistados pareceram buscar distintos modos de se adequar ao modelo de identidade previamente concebida para a área, na tentativa de encontrar reconhecimento e fugir das violências decorrentes da não adequação. Os estudantes parecem ter percebido que quanto mais distante suas performances estiverem da matriz de inteligibilidade heterossexual, menos serão reconhecidos (Butler, 1993).

Em síntese, percebemos que a heteronormatividade evidenciada na Administração compele comportamentos aos discentes do curso, sendo regida por normas que instigam a repetição de performances legitimadas e que se amparam na compreensão linear entre corpo, sexo e desejo (Borba, 2014). No entanto, a performatividade não é determinante sobre a construção da identidade profissional e da performance dos estudantes dessa graduação. Apesar de parte dos alunos LGBT buscar se adequar aos ditames da matriz de inteligibilidade, outras performances "desviantes" mostraram a existência de espaços de mudança e subversão à lógica performativa, por mais que a hegemonia heterossexual se mostre como ideologia dominante.

\section{- CONSIDERAÇÕES FINAIS}

A presente pesquisa apresentou indicativos de que a performatividade sobre a Administração parece reforçar a pré-condição sobre a orientação sexual capaz de promover reconhecimento no curso (discurso heterossexual). A partir da performatividade, as práticas discursivas e sociais são produzidas, 
e as performances são moldadas com base nos códigos de significação presentes na matriz heterossexual (Butler, 2017). Decorrente deste contexto apresentado, os corpos dos discentes circunscritos no curso tendem a ser regulados e naturalizados pela sexualidade, com base num conjunto de imposições estabelecidas a partir da compulsoriedade heterossexual e da heteronormatividade (Butler, 1993; Filax, Sumara, Davis, \& Shogan, 2015).

O reforço ideológico da heteronormatividade sobre o diferente sustenta relações de dominação, delimita espaços de convivência e de atuação aos atores sociais, além de legitimar estruturas sociais (Fairclough, 2016). Somos levados a acreditar que a matriz heterossexual possibilita certo controle social na Administração a partir de elementos legitimados e universalizantes que formam o modelo tradicional e as performances esperadas por um(a) administrador(a), os quais buscam conformar os corpos discentes sobre identidades previamente arquitetadas (Pinto, 2007).

Apesar da pressão performativa sofrida, a performance dos corpos nem sempre é exercida com base no que a performatividade induz (Butler, 2017; Borba, 2014). Há discentes que tentam, em alguns momentos específicos, subverter a matriz de poder que sustenta a heteronormatividade - como ilustram alguns dos enunciados apresentados dos (ou sobre os) discentes Júnior e Lorenzo, seja pelo modo de se vestir, pela manutenção do comportamento afeminado e/ou pela preservação de atos de fala comuns ao ethos LGBT -, o que costuma ter como consequências atos de recriminação, preconceito, discriminação e exclusão.

Todavia, os atos de subversão são pontuais e esporádicos. Os relatos pareceram reforçar que a busca por reconhecimento no curso e na carreira profissional a construir está condicionada ao discurso que nomeia, categoriza e hierarquiza os corpos sociais, tanto em relação à orientação sexual quanto às questões de gênero (Butler, 1993). A recusa ao feminino, explicitada em diversos fragmentos discursivos na seção 5 , pode ser interpretada como parte estruturante do discurso excludente que caracteriza tanto o curso quanto a profissão na Administração.

No caso dos discentes LGBT, parecem sobrar dois caminhos possíveis: o silenciamento e a adequação da performance ou as sensações de incompletude e de instabilidade na vida profissional. Tais sensações são alimentadas pelo aparelhamento ideológico que parece alertar de forma recorrente acerca da inconformidade de sua performance às normas discursivas heteronormativas sobrepostas à Administração.

$O$ anseio que tivemos por trazer a heteronormatividade ao debate na Administração encontrou como primeira barreira o fato de o discurso hegemônico presente na graduação estar ligado justamente à matriz de inteligibilidade sustentada sob a ordem moral concebida a partir do ideal de normalidade. Sendo assim, acreditamos que o curso deve ser repensado e reestruturado a fim de contemplar sujeitos que destoam e resistem aos padrões limitantes e excludentes, desconstruindo e reconstruindo estruturas discursivas, a fim de que reconheçam e incluam as diferenças.

Entre as principais limitações que encontramos destacamos a dificuldade em acessar os atores da pesquisa - talvez motivada pela temática do estudo em confronto com a heteronormatividade discorrida nas análises e nestas 
considerações finais. A temática que aqui discutimos pode ainda render estudos futuros a partir do discurso de docentes, coordenadores e chefes de departamento, e em outras IES privadas e públicas, a fim de ampliar e reforçar as conclusões sobre o discurso heteronormativo no curso e seus desdobramentos.

\section{DEFERÊNCIAS}

Benschop, Y., \& Doorewaard, H. (1998). Covered by equality: the gender subtext of organizations. Organizations Studies, 19(5), 787-805.

Berlant, L., \& Warner, M. (1998). Sex in public. Critical Inquiry, 24(2), 547.

Borba, R. (2014). A linguagem importa? Sobre performance, performatividade e peregrinações conceituais. Cadernos Pagu, 43(2), 441-474.

Bourdieu, P. (1996). Novas reflexões sobre a dominação masculina. In Lopes, M. J. M., Meyer, D. E., \& Waldow, V. R. (Orgs.). Gênero e Saúde. Porto Alegre: Artes Médicas.

Brasil (2005). Diretrizes curriculares nacionais do curso de graduação em Administração. Resolução n 4, 13 de julho de 2005. Brasil: Ministério da Educação. Recuperado em 1 março, 2019, de http://portal.mec.gov.br/component/content/ article?id=12991

Bravo, J. (2015). Do "Eu" ao "Outro": a estilização do corpo queer. Periódicus: Revista de estudos indisciplinares em gênero e sexualidades, 3(1).

Burbules, N. C. (2008). Uma gramática da diferença: algumas formas de repensar a diferença e a diversidade nos tópicos educacionais. In Garcia, R. L. \& Moreira, A. F. B. (Orgs.). Currículo na contemporaneidade: incertezas e desafios. (3a Ed.) São Paulo: Cortez.

Butler, J. (1993). Critically Queer. GLQ: A Journal of Lesbian and Gay Studies, (1), 17-32. Butler, J. (1993a). Bodies that matter: on the discursive limits of "sex". Nova York: Routledge.

Butler, J. (1998). Fundamentos contingentes: o feminismo e a questão do "pósmodernismo". Cadernos Pagu, 11, 11-42.

Butler, J. (2017). Problemas de gênero: feminismo e subversão da identidade. $13^{a}$ Ed. Rio de Janeiro: Civilização Brasileira.

Cameron, D. (1995). Verbal hygiene. London: Routledge.

Cameron, D., \& Kulick, D. (2003). Language and sexuality. Cambridge: CUP.

Cappelle, M. C. A., Melo, M. C. O. L., \& Souza, N. L. (2013). Mulheres, trabalho e administração. RIGS - Revista Interdisciplinar de Gestão Social, 2(2), 161-191.

Colling, L. (2018). Gênero e sexualidade na atualidade. Salvador: UFBA, Instituto de Humanidades, Artes e Ciências; Superintendência de Educação a Distância.

Derrida, J. (1990). Limited Inc. Paris: Éditions Galilée.

Fairclough, N. (2012). Análise crítica do discurso como método em pesquisa social científica (I. F. Melo, Trad.). Linha D’Àgua, 25(2), 307-329. 
Fairclough, N. (2016). Discurso e mudança social. 2a ed. Brasília: Editora Universidade de Brasília.

Filax, G., Sumara, D., Davis, B., \& Shogan D. (2015). Teoria Queer/Abordagem lésbica e gay. In Somekh, B., \& Lewin, C. (Orgs.). Teoria e métodos de pesquisa social. Petrópolis/RJ: Vozes.

Fleury, M. T. L. (2000). Gerenciando a diversidade cultural: experiências de empresas brasileiras. RAE (Revista de Administração de Empresas), 40(3), 18-25.

Goffman, E. (1959). The Presentation of self in everyday life. Nova York: Anchor Books.

Hanashiro, D. M. M., \& Torres, C. V. (2010). Introdução de edição especial. RAM (Revista de Administração Mackenzie), 11(3), 2-5.

Hearn, J. (1992). Changing men and changing managements: a review of issues and actions. Women In Management Review, 7(1), 2-9.

Higashi, R. (2016). A heteronormatividade e a graduação em Administração. Dissertação de Mestrado, Universidade Federal do Espírito Santo, Vitória, ES, Brasil.

Jagger, G. (2008). Judith Butler: sexual politics, social change and the power of the performative. Nova York: Routledge.

Jagose, A. (1996). Queer theory: an introduction. New York: New York University Press.

Kelan, E. K. (2013). The becoming of business bodies: gender, appearance, and leadership development. Management Learning, 44(1), 45-61.

Lorentz, C. N. (2014). Diversidade e reconhecimento da diferença: um estudo no âmbito organizacional. Tese de Doutorado, Universidade Federal de Minas Gerais, Belo Horizonte, MG, Brasil.

Louro, G. (2016). Um corpo estranho: ensaios sobre a sexualidade e teoria queer. (2a Ed., 3a reimp.). Belo Horizonte: Autêntica.

Martins, P. et al (1997). Repensando a formação do administrador brasileiro. Archétypon, 15(5), 11-30.

Miskolci, R., \& Pelúcio, L. (2007). Fora do sujeito e fora do lugar: reflexões sobre performatividade a partir de uma etnografia entre travestis. Gênero, 7(2), 257-269.

Morgan, G. (2007). Imagens da Organização. (2a Ed). São Paulo: Editora Atlas S.A. Moura, R. G., \& Lott, A. C. O. (2016). Segmento LGBTT: uma análise de artigos publicados em periódicos nacionais de 2000 a 2015. Anais do Encontro da ANPAD, Costa do Sauípe, BA, Brasil, 40.

Moura, R. G., Nascimento, R. P., \& Barros, D. F. (2017). O problema não é ser gay, é ser feminino: o gay afeminado nas organizações. FAROL - Revista de Estudos Organizacionais e Sociedade, 4(11).

Nkomo, S. M., \& Cox, T. (1999). Diversidade e identidade nas organizações. In Clegg, S. R. \& Hardy, C. (Orgs.). Handbook de estudos organizacionais: modelos de análise e novas questões em estudos organizacionais. (1a Ed., vol. 1). São Paulo: Atlas.

Orlandi, E. P. (2002). Análise de discurso: princípios e procedimentos. 4a Ed. Campinas/SP: Pontes.

Ozturk, M., \& Rumens, N. (2014). Gay male academics in UK Business and Management schools: negotiating heteronormativities in everyday work life. British Journal of Management, 25(3), 503-517. 
Petinelli-Souza, S. (2013). Constituição e formação do sujeito administrador. Administração: Ensino e Pesquisa, 14(3), 453-483.

Pinto, J. (2007). Conexões teóricas entre performatividade, corpo e identidades. D.E.L.T.A, 23(1), 1-26.

Reed, M. (2007). Teorização organizacional: um campo historicamente contestado. In Clegg, S. R., Hardy, C. \& Nord, W. R. (Orgs.). Handbook de Estudos Organizacionais V. 1. São Paulo: Editora Atlas S.A.

Rumens, N. (2016). Towards queering the business school: a research agenda for advancing lesbian, gay, bisexual and trans perspectives and issues. Gender, Work \& Organization, 23(1), 36-51.

Saraiva, L. A. S. (2016). Metonímia de um extermínio: a violência contra a população LGBT. FAROL - Revista de Estudos Organizacionais e Sociedade, 3(7).

Saraiva, L. A. S., Santos, L. T., \& Pereira, J. R. (2019). Heteronormatividade, masculinidade e preconceito em aplicativos de celular: o caso do Grindr em uma cidade brasileira. BBR - Brazilian Business Review, 17(1), 114-131.

Shimada, N. E., \& Crubellate, J. M. (2012). A constituição do administrador profissional. Caderno de Administração, 20(2).

Silva, T. T. (2013). Documentos de identidade: uma introdução às teorias do currículo. (3a Ed., 4 reimp.) Belo Horizonte: Autência Editora.

Somekh, B., \& Lewin, C. (2015). Glossário. In Somekh, B. \& Lewin, C. (Orgs.). Teoria e métodos de pesquisa social. Petrópolis/RJ: Vozes.

Souza, E. (2009). O mito da igualdade: análise pós-estruturalista das políticas de diversidade promovidas por bancos públicos e privado. Anais do Encontro de Gestão de Pessoas e Relações de Trabalho da ANPAD, Curitiba, PR, Brasil, 2.

Souza, E. (2017). A teoria queer e os estudos organizacionais: revisando conceitos sobre identidade. RAC, 21(3), 308-326.

Souza, E. M., \& Carrieri, A. P. (2010). A analítica queer e seu rompimento com a concepção binária de gênero. Rev. Adm. Mackenzie (RAM), 11(3), Edição Especial.

Sullivan, N. (2003). A critical introduction to queer theory. New York: New York University Press.

Swain, T. (2001). Para além do binário: os queers e o heterogêneo. Gênero, 2(1), 87-98.

Swain, T. (2009). Heterogênero: "uma categoria útil de análise". Educar, 35, 23-36.

Swan, E., Stead, V., \& Elliott, C. (2009). Feminist challenges and futures: women, diversity and management learning. Management Learning, 40(4), 431-437.

Teixeira, J. C., Perdigão, D. A., \& Carrieri, A. P. (2016). O discurso gerencialista e a construção de ideais estéticos femininos e masculinos. FAROL - Revista de Estudos Organizacionais e Sociedade, 3(7). 